\title{
Effects of pH and Concentrations of Linoleic and Linolenic Acids on Extent and Intermediates of Ruminal Biohydrogenation in Vitro
}

\author{
A. Troegeler-Meynadier, ${ }^{\star}$ M. C. Nicot, ${ }^{\star}$ C. Bayourthe, $\dagger$ \\ R. Moncoulon, $†$ and F. Enjalbert* \\ *Ecole Nationale Vétérinaire, Département Elevage \\ and Produits, Laboratoire d'Alimentation, \\ 31076 Toulouse Cedex, France and \\ †Ecole Nationale Supérieure Agronomique, \\ Laboratoire d'Ingénierie Agronomique, \\ 31326 Castanet Tolosan Cedex, France
}

\begin{abstract}
Three experiments were conducted by in vitro incubations in ruminal fluid to investigate the effects of $\mathrm{pH}$ and amounts of linoleic and linolenic acids on the extent of their biohydrogenation, the proportions of conjugated linoleic acid (CLA) and trans-C18:1 as intermediates, and the ratio trans-10:trans-11 intermediates. The effects of $\mathrm{pH}$ and amount of linoleic acid were investigated in kinetic studies, and effects of the amount of linolenic acid were studied with 6 -h incubations. With identical initial amounts of linoleic acid, its disappearance declined when the mean $\mathrm{pH}$ during incubation was under 6.0 compared with a mean $\mathrm{pH}$ over 6.5, and when the amount of linolenic acid increased from 10 to $180 \mathrm{mg} / 160-\mathrm{ml}$ flask, suggesting an inhibition of the isomerization step of the biohydrogenation. Low $\mathrm{pH}$ decreased the ratio of trans-10:trans11 intermediates. With initial amounts of linoleic acid increasing from 100 to $300 \mathrm{mg}$, the percentage of linoleic acid disappearance declined, but the amount that disappeared increased, without modification of the trans-10:trans-11 ratio, suggesting a maximal capacity of isomerization rather than an inhibition. Moreover, increasing initial linoleic acid resulted in high amounts of trans-C18:1 and an increase of C18:0 that was a linear function of time, suggesting a maximal capacity for the second reduction step of biohydrogenation. High amounts of initial linolenic acid did not affect the amounts of CLA, trans-C18:1, or the ratio trans-10:trans-11. Based on these experiments, a ruminal $\mathrm{pH}$ near neutrality with high amount of dietary linoleic acid should modulate the reactions of biohy-
\end{abstract}

Received May 6, 2003.

Accepted August 12, 2003.

Corresponding author: A. Troegeler-Meynadier; e-mail: a. meynadier@envt.fr. drogenation in a way that supports CLA and trans$11 \mathrm{C} 18: 1$ in the rumen.

(Key words: biohydrogenation, conjugated linoleic acid, in vitro, polyunsaturated fatty acids)

Abbreviation key: BH = biohydrogenation, CLA = conjugated linoleic acid, FA = fatty acids, $\mathbf{H p H}=$ highpH buffer, LpH = low-pH buffer, PUFA = polyunsaturated fatty acids, $\mathbf{t 1 0}$ FA = trans-10C18:1 + trans -10 , cis $-12 \mathrm{C} 18: 2, \mathbf{t 1 1 F A}=$ trans $-11 \mathrm{C} 18: 1+$ cis -9 , trans 11C18:2.

\section{INTRODUCTION}

Conjugated linoleic acid (CLA) groups positional and geometric isomers of linoleic acid (cis-9,cis12C18:2, which will be referred as cis-C18:2) (Ha et al., 1989). Among them, cis-9,trans-11C18:2 and trans10,cis-12C18:2 are the most abundant in the human food (Chin et al., 1992), and have been shown to have specific dietetic properties: cis-9,trans-11C18:2 inhibits carcinogenesis (Parodi, 1999) and trans-10,cis12C18:2 affects lipid metabolism (Park et al., 1999). Moreover, in laboratory animals, CLA has been shown to modulate atherogenesis (Nicolosi et al., 1993), diabetes (Houseknecht et al., 1998), and immunity (Yamasaki et al., 2000), but the responsible isomer(s) is (are) still unknown. The major sources of CLA for human are milk and dairy products (Chin et al., 1992), so that an increase of CLA content in cow's milk would increase CLA intake with possible beneficial effects on consumer's health.

Conjugated linoleic acid of milk originates from ruminal biohydrogenation (BH) of dietary cis-C18:2 and linolenic acid (cis-9, cis-12, cis-15C18:3, which will be referred as cis-C18:3). The $\mathrm{BH}$ of $c i s-\mathrm{C} 18: 2$ is divided into three steps: isomerization to CLA, reduction of CLA to trans-C18:1 by a first reductase, and reduction of trans-C18:1 to C18:0 by a second reductase. Initial 
isomerization produces trans- 11 and presumably trans-10 isomers (Griinari and Bauman, 1999). The $\mathrm{BH}$ of cis-C18:3 comprises four steps (Griinari and Bauman, 1999): isomerization to conjugated cis-C18:3, and three successive reductions that produce $\mathrm{C} 18: 2$ isomers other than CLA, cis or trans isomers of C18:1 and finally C18:0, respectively.

A minor part of CLA in milk comes directly from ruminal CLA, but most milk cis-9, trans-11C18:2 is synthesized in the mammary gland by desaturation of trans-11C18:1 (Griinari et al., 2000), which is the main trans-C18:1 produced by $\mathrm{BH}$ of cis-C18:2. Whatever the origin of milk CLA, factors affecting $\mathrm{BH}$ would be able to modulate CLA contents in milk. Ruminal $\mathrm{pH}$ and source and amount of polyunsaturated fatty acids (PUFA) are known to affect quantitatively the extent of BH (Van Nevel and Demeyer, 1996; Griinari and Bauman, 1999; Beam et al., 2000). From a qualitative point of view, Griinari et al. (1998) noticed that acid conditions in the rumen increase trans-10C18:1 in milk. However, the effects of $\mathrm{pH}$ and PUFA on the intermediates of $\mathrm{BH}$ in the rumen have not been extensively studied (Kucuk et al., 2001; Meynadier et al., 2002).

Our purpose was to investigate in vitro the effect of $\mathrm{pH}$ and PUFA source and amount on the extent of $\mathrm{BH}$ of PUFA, on the proportions of CLA and trans-C18:1, and on the equilibrium between (trans-10C18:1 + trans-10, cis-12C18:2) (t10 FA) and (trans-11C18:1 + cis-9, trans-11C18:2) (t11FA) during ruminal incubations.

\section{MATERIALS AND METHODS}

\section{Description of Experiments}

Three experiments were conducted in vitro to investigate the effects of $\mathrm{pH}$, amount of cis-C18:2, and the amount of cis-C18:3 on BH of PUFA. Incubation times were $2,4,8,16$, and $24 \mathrm{~h}$ in Exp. 1 and 2, and $6 \mathrm{~h}$ in Exp. 3. The buffer solutions were based on phosphate and bicarbonate, which have both been previously used by others in experiments on BH (Kim et al., 2000; Martin and Jenkins, 2002; Meynadier et al., 2002; Wang et al., 2002; Enjalbert et al., 2003). In Exp. 1, the 2 buffer solutions resulted in an initial $\mathrm{pH}$ near 6 and 7 , and were called low $\mathrm{pH}(\mathbf{L p H})$ and high $\mathrm{pH}$ $(\mathbf{H p H})$, respectively.

Fatty acid (FA) compositions of added fat for the 3 experiments are shown in Table 1. In Exp. 1, added fat was soybean oil. In Exp. 2, 100 or $300 \mathrm{mg}$ of cisC18:2 was associated with a constant amount of other FA, and in Exp. 3, 10, 60, 120, or $180 \mathrm{mg}$ of cis-C18:3 was associated with a constant amount of other FA; in both experiments, a mixture of oils (canola, linseed, olive, soybean, grapeseed), tripalmitin (Sigma-Aldrich Chimie, St. Quentin Fallavier, France), and tristearin (ICN Biomedicals Inc., Orsay, France) was used.

\section{In Vitro Cultures}

Incubations were accomplished in a waterbath rotary shaker (Aquatron; Infors AG, 4103 Bottmingen, Germany). Ruminal fluid was obtained from 2 fistulated dry cows receiving $8.5 \mathrm{~kg}$ of $\mathrm{DM}$ of a blend of corn silage and concentrates, and orchardgrass hay ad libitum. One liter of ruminal fluid was taken from each cow with a vacuum pump $1 \mathrm{~h}$ after feeding, and strained through a metal sieve $(1.6 \mathrm{~mm}$ mesh). The ruminal fluids obtained from the 2 cows were mixed in a bottle and transferred (30 $\mathrm{min})$ to the laboratory under anaerobic conditions at $39^{\circ} \mathrm{C}$.

Eighty milliliters of this mixed ruminal fluid and $80 \mathrm{ml}$ of a buffer solution were placed in a $250-\mathrm{ml}$ Erlenmeyer flask containing added fat and $3 \mathrm{~g}$ of dehydrated alfalfa. All buffer solutions were prewarmed at $39^{\circ} \mathrm{C}$ and saturated with $\mathrm{CO}_{2}$ when containing bicarbonate. The filled flasks were gassed with $\mathrm{CO}_{2}$ and placed in the waterbath at $39^{\circ} \mathrm{C}$. They were closed in order to clear out fermentation gas without entrance of oxygen and stirred at $130 \mathrm{rpm}$. They were kept from light during incubation.

Six replicates, in 2 or 3 series of incubations, were realized for each $\mathrm{pH}$, each amount of PUFA, and each incubation time. For each incubation time and each buffer solution in each series, a control flask without added fat was incubated. Incubations were stopped by placing the flasks into iced water, and $\mathrm{pH}$ was then measured. The contents of the flasks were frozen, freeze-dried (Virtis Freezemobile 25; Virtis, Gardiner, NY), weighed, ground, homogenized in a ball mill (Dangoumau, distributed by Prolabo, Nogent-surMarne, France), and kept at $-18^{\circ} \mathrm{C}$ until analysis.

\section{Analysis of Fatty Acids}

The FA of feed samples and residues of incubation were extracted and methylated with the 1-step procedure of Sukhija and Palmquist (1988), after addition of C19:0 as an internal standard. This method is known to lead to underestimation of cis-9,trans11C18:2 and trans-10,cis-12C18:2 by 41 and $44 \%$, respectively, due to isomerization during transmethylation (Duckett et al., 2002). Therefore, the values for CLA isomers presented in this article can only be used for comparisons within this experiment, not for comparisons with values obtained by others with different analytical methods. The FA methyl esters were then quantified by gas chromatography (Agilent 6890N, 
Table 1. Amount of added fatty acids in Experiments 1, 2, and 3 (mg/flask).

\begin{tabular}{lccl}
\hline Fatty acid & Experiment 1 & Experiment 2 & Experiment 3 \\
\hline C16:0 & 9.9 & 29.9 & 16.5 \\
C18:0 & 3.7 & 17.0 & 11.6 \\
cis-9C18:1 & 19.2 & 60.8 & 49.0 \\
cis-9,cis-12C18:2 & 46.5 & 100 or 300 & 44.5 \\
cis-9,cis-12, cis-15C18:3 & 6.4 & 1.5 & $10,60,120$, or 180 \\
\hline
\end{tabular}

equipped with a model 7683 auto injector, Network GC System, Palo Alto, CA). The column was a fused silica capillary (CPSil88, $100 \mathrm{~m} \times 0.25 \mathrm{~mm}$ id, 0.20 $\mu \mathrm{m}$ film thickness; Chrompack-Varian, Middleburg, The Netherlands). A first analysis was made using the method described by Enjalbert et al. (2003). A second analysis, using different patterns of oven temperature, allowed the separation of trans-10C18:1 and trans$11 \mathrm{C} 18: 1$; the oven temperature was $72^{\circ} \mathrm{C}$ for $15 \mathrm{~min}$ and then increased by $45^{\circ} \mathrm{C} / \mathrm{min}$ until $160^{\circ} \mathrm{C}$, maintained at $160^{\circ} \mathrm{C}$ for $60 \mathrm{~min}$ and then increased by $5^{\circ} \mathrm{C} /$ min until $225^{\circ} \mathrm{C}$, and was then maintained at $225^{\circ} \mathrm{C}$ for $10 \mathrm{~min}$. Peaks were identified and quantified by comparison with commercial standards (Sigma, St. Louis, MO).

\section{Calculations and Statistics}

Amount of added fat in each culture was computed as the difference in the amount of fatty acid between control and added fat cultures in the same series, measured after incubation. The amount of $\mathrm{C} 18: 0$ resulting from $\mathrm{BH}$ of PUFA was calculated by subtracting from the C18:0 from added fat, the C18:0 initially present in added fat, and that resulting from $\mathrm{BH}$ of cis-9C18:1, which was the only other unsaturated FA present in added fats used in these 3 experiments. Although a small amount (about 3\%) of cis-9C18:1 can be isomerized to trans-C18:1 (Ward et al., 1964; Loor et al., 2002; Mosley et al., 2002), we considered that all disappeared cis-9C18:1 was converted to C18:0.

The estimation of $\mathrm{BH}$ was based on the disappearance of the unsaturated FA (Beam et al., 2000; Enjalbert et al., 2003). For all experiments, this disappearance was expressed as flux of PUFA loss $(\mathrm{mg} /[\mathrm{ml} \cdot \mathrm{h}])$. For Exp. 1 and 2, we estimated the parameters of $\mathrm{BH}$ kinetics with the exponential model of Orskov and McDonald (1979), adapted for the BH of FA in vitro as described by Enjalbert et al. (2003). As previously described (Kepler and Tove, 1967; Harfoot et al., 1973) in our Exp. 1 and 2, a complete BH of PUFA could not be expected from the kinetics curves of $\mathrm{BH}$, so we added a fraction escaping $\mathrm{BH}$ to the model. The final model was:

$$
P_{t}=P_{0} \times(1-\mathrm{FEBH}) \times \mathrm{e}^{[-\mathrm{c} \times(\mathrm{t}-\mathrm{lag})]}+P_{0} \times \mathrm{FEBH},
$$

where $P_{t}=$ proportion of the UFA at $t$ h of incubation, $P_{0}=$ initial proportion of the UFA in the experimental substrate, FEBH = fraction of the UFA escaping $\mathrm{BH}$, $\mathrm{c}=$ rate of $\mathrm{BH}$, and lag = lag time before the $\mathrm{BH}$ begins .

Data were computed with the nonlinear regression procedure of SYSTAT (Version 9, SPSS Inc., Chicago, IL). The comparison between treatments of the fractions escaping $\mathrm{BH}, \mathrm{BH}$ rates, and lag times was made as described by Enjalbert et al. (2003). These 2 estimations of $\mathrm{BH}$ took into account only the lipolysis of triacylglycerols and the isomerization step of $\mathrm{BH}$. The activity of the reductases was estimated through the evolution of concentrations of the $\mathrm{BH}$ intermediates.

The proportions of each FA, the ratio t10FA:t11FA at each time of incubation and the flux of PUFA loss were compared between treatments using the general linear model of SYSTAT, followed by the Tukey's pairwise comparison test when more than two treatments were compared. Differences were considered significant at $P<0.05$.

\section{RESULTS AND DISCUSSION}

\section{Effect of pH on Biohydrogenation}

During Exp. 1, the $\mathrm{pH}$ of $\mathrm{HpH}$ cultures decreased from 6.9 to 6.4, whereas $\mathrm{pH}$ in $\mathrm{LpH}$ cultures decreased from 6.2 to 5.4 so that the difference between treatments was always above $0.7 \mathrm{pH}$ units (Figure 1).

The lag times were between 1 and $2 \mathrm{~h}$ except for cisC18:3 with $\mathrm{LpH}$ (Table 2). This lag time could be due to the time necessary for lipolysis, which is between 2 and $4 \mathrm{~h}$ for soybean oil (Reddy et al., 1994), and/ or the time necessary for a multiplication of rumen bacteria in order to have a sufficient amount of bacteria to lipolyze and hydrogenate fat. Indeed, bacteria are fixed onto feed particles, and strained ruminal fluid contains few feed particles. Beam et al. (2000), in their strained ruminal fluid cultures, also noticed a lag time between 1.39 and $2.47 \mathrm{~h}$, which they attributed to the time necessary for lipolysis of soybean oil. Because in the present experiment, and with both treatments, the 


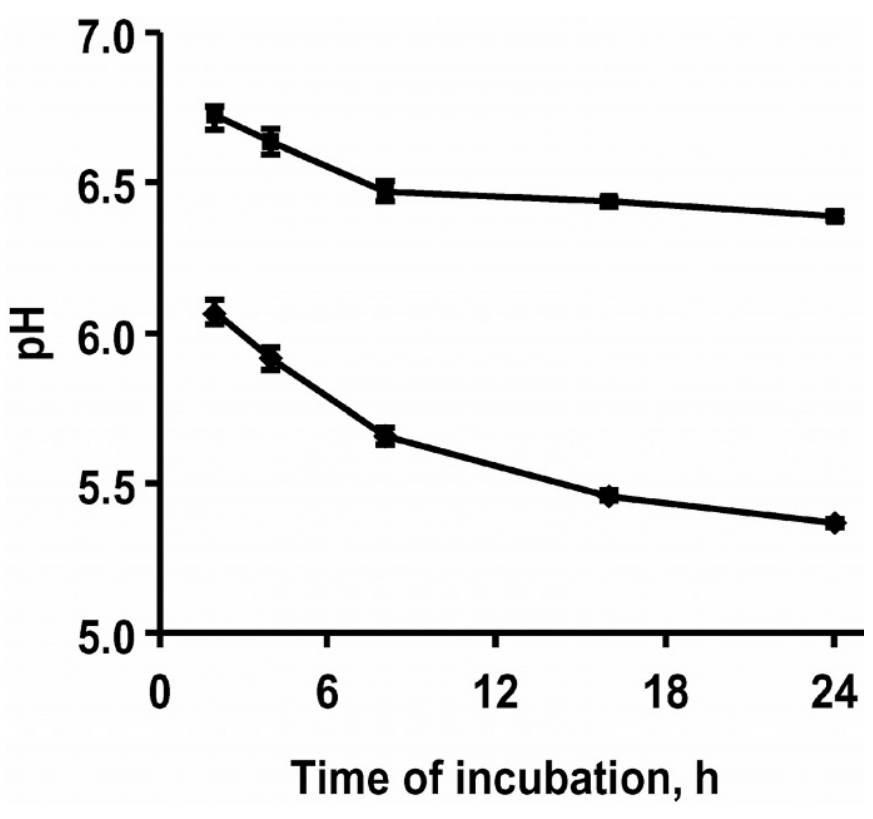

Figure 1. Evolution of pH during low-pH buffer $(\diamond)$ and high-pH buffer (ם) in vitro incubations in Experiment 1.

$\mathrm{pH}$ was over 5.9 at 2 and $4 \mathrm{~h}$ of incubation, there was no inhibition of lipolysis (Van Nevel and Demeyer, 1996).

The proportion of cis-C18:2 escaping BH was 4 times higher with $\mathrm{LpH}$ than with $\mathrm{HpH}$. On the contrary, but with both buffers, the proportion of cis-C18:3 escaping $\mathrm{BH}$ was not different from zero (Table 2).

With $\mathrm{HpH}$, the flux of disappearance of cis-C18:2 and cis-C18:3 were higher $(P>0.01$ and $P>0.05$, respectively) than with $\mathrm{LpH}$ (Table 3 ) after $2 \mathrm{~h}$ of incubation. Similarly, the rate of disappearance of PUFA, with $\mathrm{LpH}$ was about one-half that of $\mathrm{HpH}$ for cis-C18:2 and cis-C18:3 (Table 2).

Table 2. Fraction escaping biohydrogenation (FEBH), lag time, and rate of biohydrogenation of polyunsaturated fatty acids from soybean oil (mean \pm SEM), Experiment 1 .

\begin{tabular}{|c|c|c|}
\hline Buffer & $\mathrm{LpH}^{1}$ & $\mathrm{HpH}^{1}$ \\
\hline \multicolumn{3}{|l|}{ cis-9,cis-12C18:2 } \\
\hline FEBH, \% initial cis-C18:2 & $20.90 \pm 4.70^{\mathrm{ab}}$ & $5.50 \pm 2.40^{\mathrm{ac}}$ \\
\hline Lag time, $\mathrm{h}$ & $1.28 \pm 0.34^{\mathrm{a}}$ & $1.89 \pm 0.13^{\mathrm{a}}$ \\
\hline $\begin{array}{l}\text { Rate of biohydrogenation, } \% / \mathrm{h} \\
\mathrm{r}^{2}\end{array}$ & \multicolumn{2}{|c|}{0.96} \\
\hline cis-9,cis-12,cis-15C18:3 & & \\
\hline FEBH, \% initial cis-C18:3 & $8.30 \pm 11.80$ & $1.60 \pm 4.20$ \\
\hline Lag time, $\mathrm{h}$ & $0.00 \pm 0.96^{\mathrm{d}}$ & $2.09 \pm 0.20^{\mathrm{ae}}$ \\
\hline $\begin{array}{l}\text { Rate of biohydrogenation, } \% / \mathrm{h} \\
\mathrm{r}^{2}\end{array}$ & $9.50 \pm 3.50^{\mathrm{ad}}$ & $92.70 \pm 3.60^{\mathrm{ae}}$ \\
\hline
\end{tabular}

${ }^{1} \mathrm{LpH}$ refers to low-pH buffer, $\mathrm{HpH}$ refers to high-pH buffer.

${ }^{a}$ Value significantly different from zero $(P<0.05)$.

${ }^{\mathrm{b}, \mathrm{c}}$ Means in the same row with unlike superscripts differ $(P<0.01)$.

${ }^{\mathrm{d}, \mathrm{e}}$ Means in the same row with unlike superscripts differ $(P<0.05)$.
The amounts of $\mathrm{BH}$ products were always significantly lower with $\mathrm{LpH}$ than with $\mathrm{HpH}$ beyond $2 \mathrm{~h}$ of incubation, and the amounts of intermediates were very close after 16 and $24 \mathrm{~h}$ of incubation (Figure 2). Wang et al. (2002) and Martin and Jenkins (2002) also noticed at low $\mathrm{pH}$ in vitro decrease of cis-C18:2 and cis-C18:3 BH with a decrease of trans-C18:1 and CLA amounts. Similarly, in vivo, an increase of the proportion of concentrates decreases milk CLA (Griinari et al., 1998; Dhiman et al., 1999).

Low amounts of CLA observed with $\mathrm{LpH}$ could be due either to low isomerase activity or to high reductase activity. Low amounts of trans-C18:1 and C18:0 from $\mathrm{BH}$ of PUFA with $\mathrm{LpH}$ did not suggest a high reductase activity. On the contrary, the low rate of disappearance of PUFA suggested that the inhibition occurred on the isomerase. Indeed, the optimal $\mathrm{pH}$ of the isomerase is between 7 and 7.2 (Kepler and Tove, 1967).

Griinari et al. (1998) found that lowering the fiber contents of a diet containing unsaturated FA reduced ruminal $\mathrm{pH}$ and resulted in a decreased proportion of trans-11C18:1 in milk and an increased proportion of trans-10C18:1. In the present experiment, LpH resulted in lower amounts of t11FA at all incubation times compared with $\mathrm{HpH}$, but amounts of t10FA were higher only at 16 and $24 \mathrm{~h}$ of incubation. This resulted in a ratio t10FA:t11FA significantly different between $\mathrm{LpH}$ and $\mathrm{HpH}(P<0.01)$, but with the same pattern during the $24 \mathrm{~h}$ of incubation (Figure 3 ). Differences between in vitro and in vivo results can be expected because the differences of $\mathrm{pH}$ in the present experiment were due to differences between buffers, not to differences between culture substrates. The trans-10 isomerase has recently been shown to be produced by Megasphaera elsdenii (Kim et al., 2002), a bacteria that utilizes lactate and develops with high-grain diets, such as the diet used by Griinari et al. (1998), but not with the diet or the culture media used in this in vitro experiment. On the contrary, a lower production of trans-11 intermediates of $\mathrm{BH}$ was observed both in the in vivo experiment of Griinari et al. (1998) and in this experiment; the trans-11 isomerase of cis-C18:2 is produced by Butyrivibrio fibrisolvens (Kepler and Tove, 1967; Kim et al., 2000), and the inhibition of cellulolytic bacteria can be mediated directly by low pH (Russell and Dombrowski, 1980).

The $\mathrm{BH}$ was not completely inhibited by $\mathrm{LpH}$ but was slowed down (Table 2 and 3). The inhibition could be reversible, either by an adaptation of the bacteria, mainly $B$. fibrisolvens, which would synthesize more enzyme, or by cell multiplication, since the CLA accumulation was shown to depend on $B$. fibrisolvens density (Kim et al., 2000). 
Table 3. Flux of disappearance of polyunsaturated fatty acids from soybean oil, Experiment 1.

\begin{tabular}{llccr}
\hline & \multicolumn{3}{c}{ Buffer } \\
\cline { 2 - 4 } Item & $\begin{array}{l}\text { Incubation } \\
\text { time, } \mathrm{h}\end{array}$ & $\mathrm{LpH}$ & $\mathrm{HpH}$ & $\mathrm{SEM}$ \\
\hline & & & $\mathrm{mg} /(\mathrm{L} \cdot \mathrm{h})$ & \\
\cline { 3 - 4 } cis-9,cis-12C18:2 & 2 & 20.80 & 27.62 & 3.09 \\
& 4 & $14.06^{\mathrm{a}}$ & $24.70^{\mathrm{b}}$ & 1.08 \\
& 8 & $15.29^{\mathrm{a}}$ & $26.58^{\mathrm{b}}$ & 1.02 \\
cis-9,cis-12,cis-15C18:3 & 16 & $12.48^{\mathrm{a}}$ & $16.37^{\mathrm{b}}$ & 0.21 \\
& 24 & $8.43^{\mathrm{a}}$ & $11.06^{\mathrm{b}}$ & 0.11 \\
& 2 & 5.75 & 2.71 & 1.70 \\
& 4 & $1.98^{\mathrm{b}}$ & $3.55^{\mathrm{c}}$ & 0.50 \\
& 8 & $2.44^{\mathrm{a}}$ & $3.83^{\mathrm{b}}$ & 0.21 \\
& 16 & $1.91^{\mathrm{a}}$ & $2.38^{\mathrm{b}}$ & 0.05 \\
& 24 & $1.29^{\mathrm{a}}$ & $1.58^{\mathrm{b}}$ & 0.03 \\
\hline
\end{tabular}

${ }^{1}$ See Figure 1.

${ }^{\mathrm{a}, \mathrm{b}}$ Means in the same row with unlike superscripts differ $(P<0.01)$.

${ }^{\mathrm{c}, \mathrm{d}}$ Means in the same row with unlike superscripts differ $(P<0.05)$.
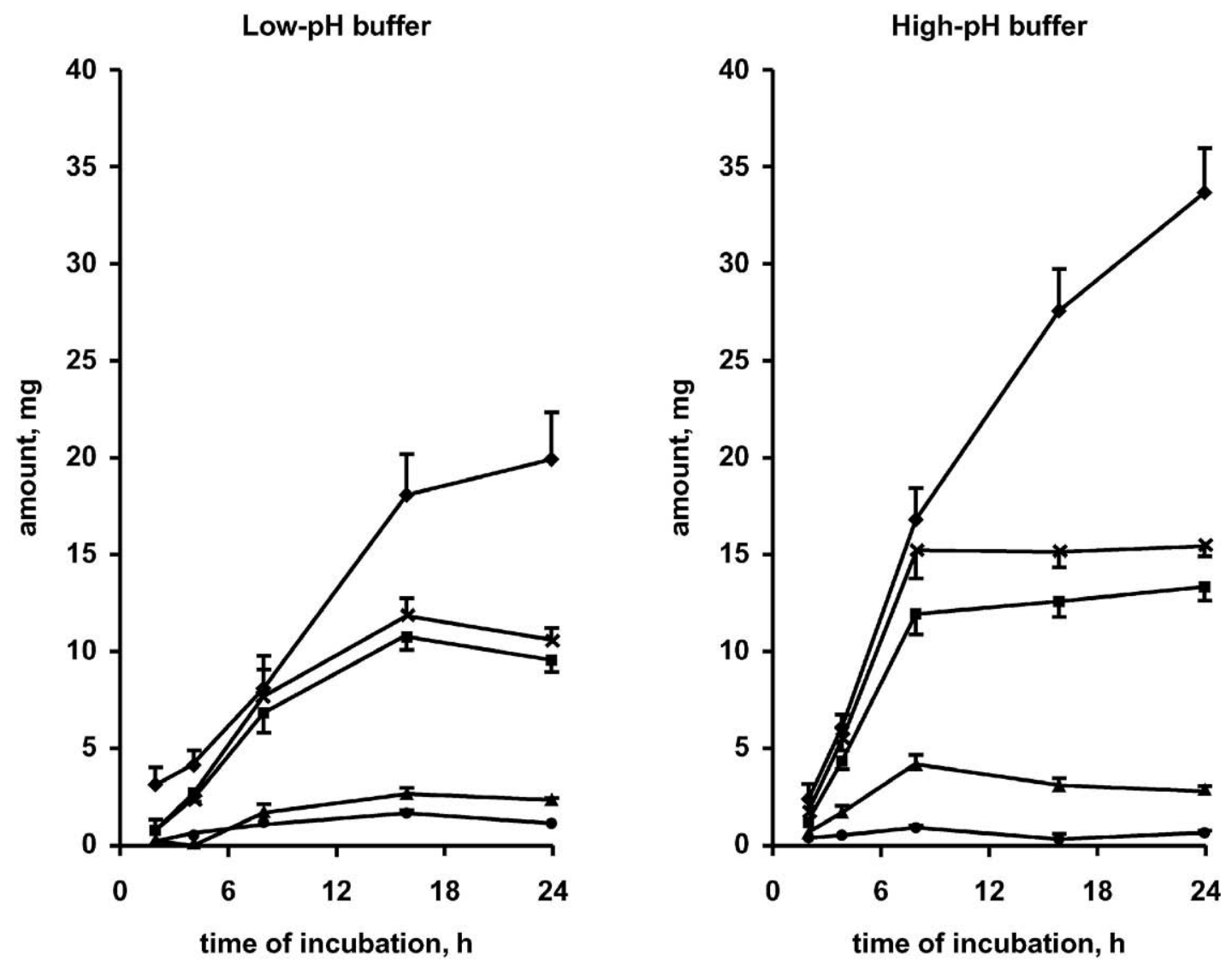

Figure 2. Effects of $\mathrm{pH}$ and incubation time on the products of biohydrogenation of polyunsaturated fatty acids: C18:0 from polyunsaturated

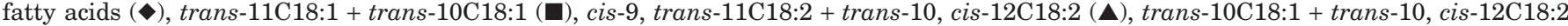
(•), and trans-11C18:1 + cis-9, trans-11C18:2 (*) in Experiment 1. 


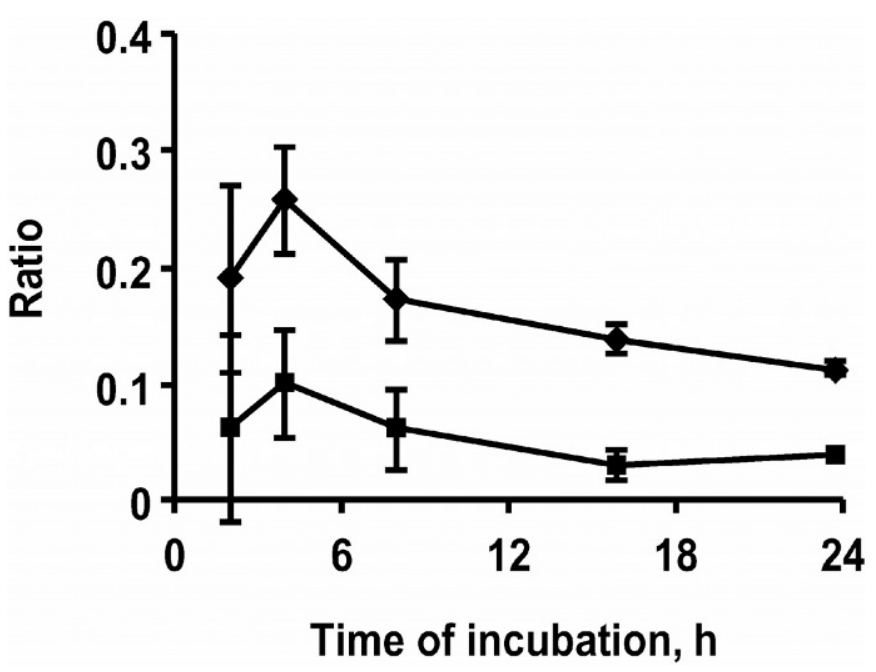

Figure 3. Effect of $\mathrm{pH}$ on the evolution over time of the (trans10C18:1 + trans-10, cis-12C182):(trans-11C18:1 + cis-9, trans11C18:2) ratio. Low-pH buffer ( ) and high-pH buffer (ם). Experiment 1 .

\section{Effect of Amount of Linoleic Acid on Biohydrogenation}

The lag time for $\mathrm{BH}$ of $c i s-\mathrm{C} 18: 2$ was the same with 100 or $300 \mathrm{mg}$ of added cis-C18:2 (Table 4), and slightly higher than in Exp. 1, which could be due to the higher amount. The fraction escaping BH was not significantly different from zero with $300 \mathrm{mg}$ of added cisC18:2.

The flux of disappearance of C18:2 was twice as great $(P<0.01)$ with 300 as with $100 \mathrm{mg}$ of added cis-C18:2 (Table 5). The rate of $c i s-\mathrm{C} 18: 2 \mathrm{BH}$ was twice as great $(P<0.05)$ with 100 as with $300 \mathrm{mg}$ of added cis-C18:2 (Table 4). This means that, when increasing the initial amount of cis-C18:2, a lower proportion of the initial amount but a higher amount of $c i s$-C18:2 disappeared due to isomerization. This suggested that the lipase or/and the isomerase, which are both necessary for disappearance of cis-C18:2 from oils, would have a maximal capacity that was reached with $300 \mathrm{mg}$ of added cis-C18:2. Lipolysis has been shown to be slower

Table 4. Fraction escaping biohydrogenation (FEBH), lag time, and rate of disappearance of linoleic acid during incubations with 100 or $300 \mathrm{mg}$ of added linoleic acid (mean \pm SEM), Experiment 2.

\begin{tabular}{lrll}
\hline Initial amount of linoleic acid, mg & \multicolumn{1}{c}{100} & \multicolumn{2}{c}{300} \\
\hline FEBH, \% initial cis-C18:2 & $11.25 \pm 2.61^{\mathrm{a}}$ & $2.21 \pm 3.59$ \\
Lag time, h & $3.09 \pm 0.22^{\mathrm{a}}$ & $3.29 \pm 0.19^{\mathrm{a}}$ \\
Rate of biohydrogenation, \%/h & $22.52 \pm 3.08^{\mathrm{ab}}$ & $12.03 \pm 1.28^{\mathrm{ac}}$ \\
$\mathrm{r}^{2}$ & \multicolumn{3}{c}{0.98} \\
\hline
\end{tabular}

${ }^{a}$ Value significantly different from zero $(P<0.05)$.

${ }^{\mathrm{b}, \mathrm{c}}$ Means in the same row with unlike superscripts differ $(P<0.01)$.
Table 5. Flux of disappearance of linoleic acid, Experiment 2.

\begin{tabular}{lllr}
\hline \multirow{2}{*}{$\begin{array}{l}\text { Incubation } \\
\text { time, } \mathrm{h}\end{array}$} & \multicolumn{2}{c}{ Initial amount of linoleic acid, mg } & \\
\cline { 2 - 3 } & 100 & 300 & SEM \\
\cline { 2 - 3 } 2 & $87.71^{\mathrm{a}}$ & $208.73^{\mathrm{b}}$ & \\
4 & $59.90^{\mathrm{a}}$ & $132.36^{\mathrm{b}}$ & 16.108 \\
8 & $53.34^{\mathrm{a}}$ & $115.49^{\mathrm{b}}$ & 8.497 \\
16 & $33.92^{\mathrm{a}}$ & $97.06^{\mathrm{b}}$ & 4.173 \\
24 & $23.41^{\mathrm{a}}$ & $69.15^{\mathrm{b}}$ & 1.338 \\
\hline \multicolumn{2}{c}{${ }^{\mathrm{a}, \mathrm{b}}$ Means in the same row with unlike superscripts $\operatorname{differ}(P<0.01)}$.
\end{tabular}

in vitro when the amount of cis-C18:2 is high (Van Nevel and Demeyer, 1996). On the contrary, Beam et al. (2000) demonstrated that increasing cis-C18:2 does not lead to a saturation of the isomerase, but their maximal concentration of cis-C18:2 was much lower than in the present experiment $(200 \mathrm{mg}$ in $200 \mathrm{ml}$ vs. $300 \mathrm{mg}$ in $160 \mathrm{ml}$ ).

Adding $300 \mathrm{mg}$ of cis-C18:2 increased the amount of its $\mathrm{BH}$ intermediates or end-product (CLA, transC18:1, C18:0) beyond $4 \mathrm{~h}$ of incubation $(P<0.01$, Figure 4 ), which is consistent with the increased amounts of CLA (Dhiman et al., 2000) and trans-C18:1 (Casper et al., 1988) in the milk from cows receiving dietary PUFA.

With $300 \mathrm{mg}$ of added cis-C18:2, the ratio of C18:0:(trans-10C18:1 + trans-11C18:1) was low compared with $100 \mathrm{mg}$ of added cis-C18:2. As shown in Figure 4, C18:0 amount increased linearly with incubation time $\left(\mathrm{C} 18: 0=3.37 \mathrm{~T}, \mathrm{r}^{2}=0.97, P<0.0001\right)$, whatever the concentration of trans-10C18:1 + trans$11 \mathrm{C} 18: 1$, suggesting that the reductase transforming trans-C18:1 to $\mathrm{C} 18: 0$ had reached a maximum capacity. Beyond this capacity, an increase of trans-C18:1 concentration would have no effect on the rate of production of $\mathrm{C} 18: 0$ so that trans-C18:1 accumulated, reaching a maximum concentration at $16 \mathrm{~h}$ of incubation. Polan et al. (1964) and Harfoot et al. (1973) also reported that when the concentration of cis-C18:2 increases in the culture media, CLA and trans-C18:1 accumulate. They suggested that this accumulation was due to an inhibition of the transformation of transC18:1 to C18:0 by cis-C18:2, and Griinari and Bauman (1999) suggested that it would be a competitive inhibition for the hydrogenation of monoenoic acids.

With either 100 or $300 \mathrm{mg}$ of cis-C18:2, from $16 \mathrm{~h}$ of incubation, the decreased amount of residual cisC18:2 resulted in slower production and decreased concentration of CLA. With $100 \mathrm{mg}$ of added cis-C18:2, this low amount of CLA limited the production of trans10C18:1 and trans-11C18:1, whose concentrations decreased because reduction to $\mathrm{C} 18: 0$ had not reached its maximum capacity. With $300 \mathrm{mg}$ of added cis- 
$100 \mathrm{mg}$ of added cis-C18:2 ${ }^{1}$

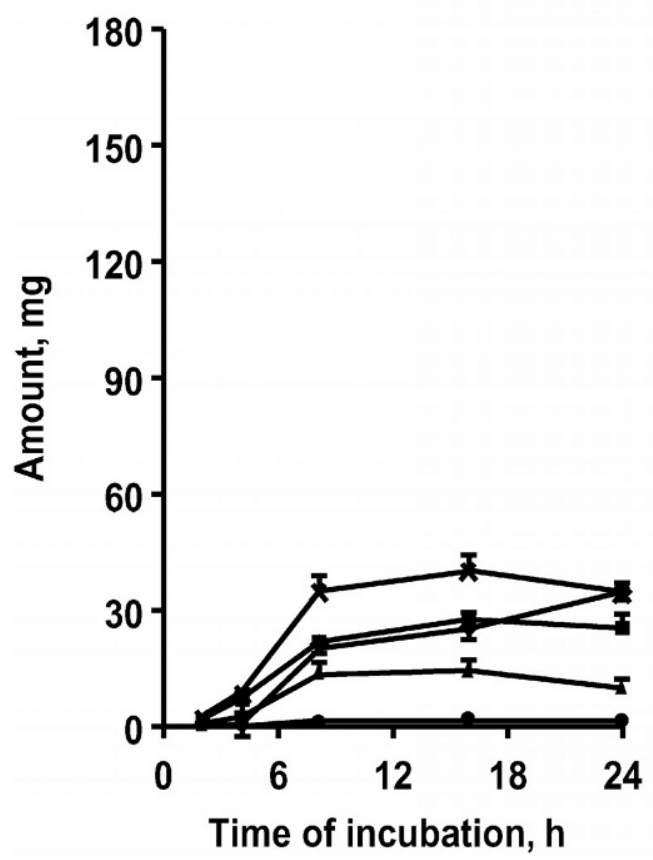

$300 \mathrm{mg}$ of added cis-C18:2 ${ }^{1}$

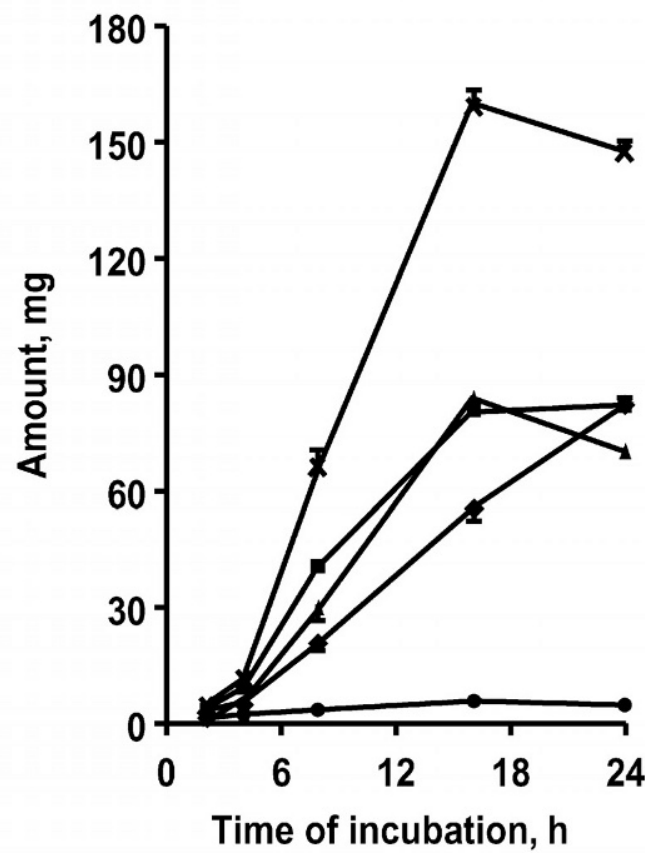

Figure 4. Effect of the amount of added linoleic acid and incubation time on the amount of its intermediates of biohydrogenation: C18:0

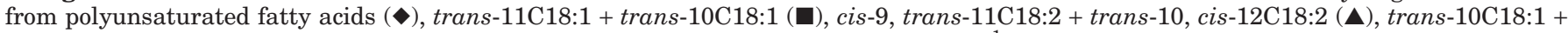
trans-10, cis-12C18:2 (৩), and trans-11C18:1 + cis-9, trans-11C18:2 (*); Experiment 2. ${ }^{1}$ cis-C18:2 refers to cis-9,cis-12C18:2.

C18:2, the concentration of trans-10C18:1 + trans11C18:1 did not decrease because of the higher concentration of CLA as a precursor and limited reduction of trans-C18:1 to C18:0 due to the limited capacity of the second reductase. The inhibition of this reductase when high concentrations of cis-C18:2 are incubated has been described as irreversible (Harfoot et al., 1973), which should result in lack of decrease of amount of trans-C18:1. Incubation times over $24 \mathrm{~h}$ should be necessary to ascertain this irreversibility. Until $16 \mathrm{~h}$ of incubation, the amount of cis-C18:2 did not affect the ratio t10FA:t11FA (Figure 5), which is consistent with the lack of effect of amount of $\mathrm{cis}$-C18:2 on the isomerization step. At $24 \mathrm{~h}$ of incubation, this ratio was lower with $300 \mathrm{mg}$ than with $100 \mathrm{mg}$ of added cis-C18:2 due to the accumulation of trans-11C18:1 with $300 \mathrm{mg}$ of $c i s-\mathrm{C} 18: 2$ at the moment when the trans-11C18:1 decreased with $100 \mathrm{mg}$ of cis-C18:2.

\section{Effect of Amount of Linolenic Acid on Biohydrogenation}

As with cis-C18:2 addition in Exp. 2, increasing the initial amount of $c i s-\mathrm{C} 18: 3$ decreased only slightly but significantly $(P<0.01)$ the proportion of cis-C18:3 that disappeared due to $\mathrm{BH}$, whereas the amount that was biohydrogenated increased nearly linearly with the initial amount (Figure 6). On the other hand, increasing the initial amount of $c i s-\mathrm{C} 18: 3$ from 10 to $180 \mathrm{mg}$

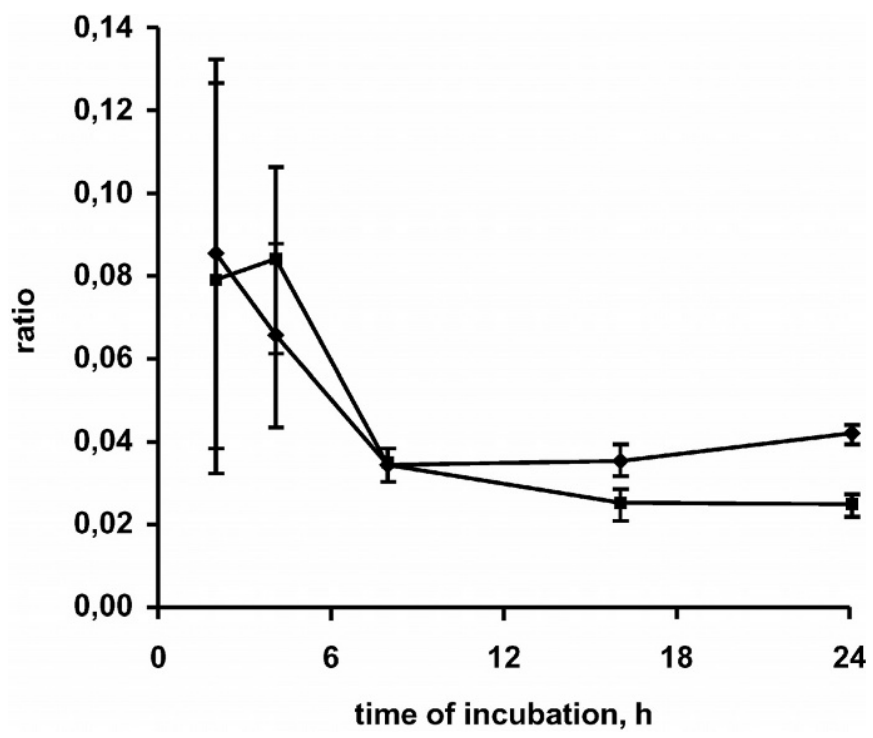

Figure 5. Effect of the addition of $100(\diamond)$ or $300 \mathrm{mg}(\boldsymbol{\square})$ of linoleic acid on the evolution over time of the (trans-10C18:1 + trans-10, cis12C182):(trans-11C18:1 + cis-9, trans-11C18:2) ratio; Experiment 2. 


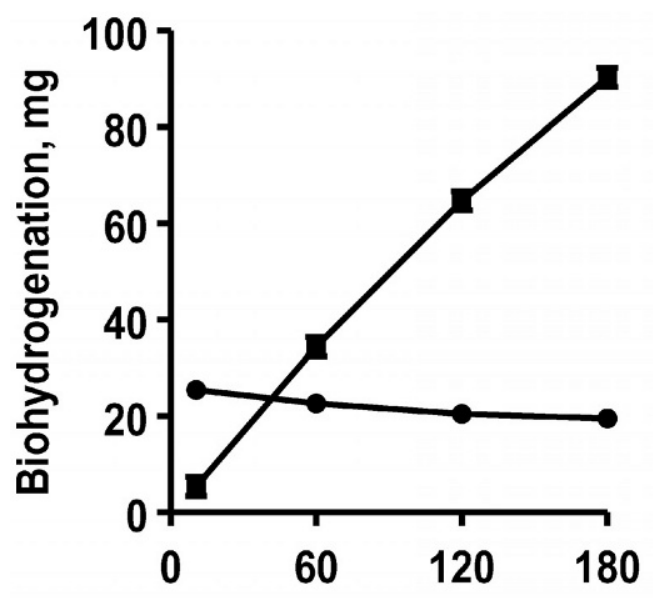

Added cis-C18: $3^{1}, \mathrm{mg}$

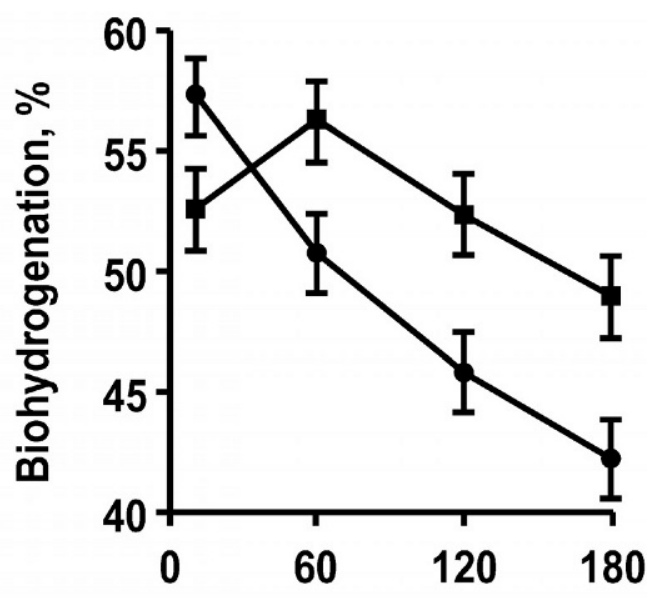

Added cis-C18: $3^{1}, \mathrm{mg}$

Figure 6. Effect of the amount of added linolenic acid on the amounts and percentages of biohydrogenation of linoleic (-) and linolenic (ם) acids after $6 \mathrm{~h}$ of incubation; Experiment 3. ${ }^{1}$ cis-9, $c i s-12$, cis-15C18:3.

decreased by $23 \%$ the amount of $c i s-\mathrm{C} 18: 2$ that disappeared after $6 \mathrm{~h}$ of incubation (Table 6). This effect was much lower than the effect of $\mathrm{pH}$ in Exp. 1: $\mathrm{LpH}$ decreased $\mathrm{BH}$ (flux of cis-C18:2 disappearance) by about $44 \%$ compared with $\mathrm{HpH}$, after 4 and $8 \mathrm{~h}$ of incubation (Table 3).

The addition of $\mathrm{cis}$-C18:3 did not affect significantly the amount of CLA and trans-10C18:1 + trans-11C18:1 after $6 \mathrm{~h}$ of incubation (Figure 7), suggesting that $\mathrm{BH}$ of cis-C18:3 did not produce significant amounts of these intermediates. Indeed, CLA isomers are not intermediates of the BH of cis-C18:3 (Kepler and Tove, 1967; Griinari and Bauman, 1999). The trans-11C18:1 is one of the monoenoic intermediates of the $\mathrm{BH}$ of cis-C18:3 (Kepler and Tove, 1967), but not the most important compared with trans-15C18:1 and cis15C18:1 (Loor et al., 2002), which were not identified by our method of analysis.

Decreased disappearance of cis-C18:2 when the amount of cis-C18:3 was high suggested an inhibition

Table 6. Flux of linoleic acid disappeared after 6 hours of incubation with different initial amounts of linolenic acid (mean \pm SEM), Experiment 3 .

\begin{tabular}{ll}
\hline $\begin{array}{l}\text { Initial amount } \\
\text { of linolenic acid, } \\
\text { mg/flask }\end{array}$ & $\begin{array}{l}\text { Flux of } \\
\text { cis-9,cis-12C18:2 } \\
\text { loss, } \mathrm{mg} /(\mathrm{L} \cdot \mathrm{h})\end{array}$ \\
\hline 10 & $26.38 \pm 0.75^{\mathrm{a}}$ \\
60 & $23.48 \pm 0.75^{\mathrm{be}}$ \\
120 & $21.25 \pm 0.75^{\mathrm{c}}$ \\
180 & $19.74 \pm 0.75^{\mathrm{df}}$ \\
\hline
\end{tabular}

${ }^{\mathrm{a}}$ Differs from ${ }^{\mathrm{b}, \mathrm{c}, \mathrm{d}}(P<0.05)$.

${ }^{\mathrm{e}}$ Differs from ${ }^{\mathrm{f}}(P<0.01)$. of cis-C18:2 BH at the isomerization step. Unchanged amounts of CLA and trans-C18:1 in spite of decreased cis-C18:2 disappearance suggested lower reductase activities. The ratio of t10FA:t11FA was between 0.019 and 0.036 and not significantly different among amounts of cis-C18:3, suggesting that both transformations to trans-10 and trans-11 isomers were inhib-

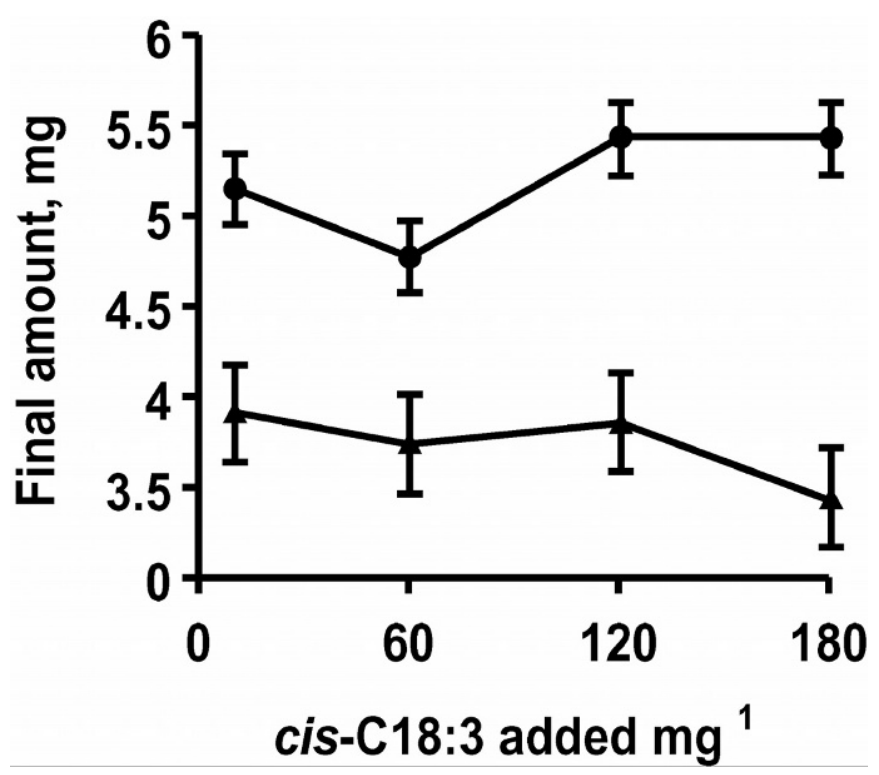

Figure 7. Effect of the amount of added linolenic acid on the amount of conjugated linoleic $\operatorname{acid}^{1}(\mathbf{\Delta})$ and trans-C18:1 ${ }^{1}(\mathbf{O})$ after 6 $\mathrm{h}$ of incubation; Experiment 3. ${ }^{1}$ trans-C18:1 refers to trans-11C18:1 and trans-10C18:1, CLA refers to cis-9, trans-11C18:2 and trans-10, cis-12C18:2, and cis-C18:3 refers to cis-9, cis-12, cis-15C18:3. 
ited. These inhibitions of isomerization and reductions could be due to a competition between cis-C18:2 and $c i s$-C18:3 for the fixation onto the envelope of the bacteria carrying isomerases, because the isomerizations of cis-C18:2 and cis-C18:3 are realized by the same bacteria and the same enzyme (Kepler et al., 1966; Kepler and Tove, 1967), and probably to other competitive inhibitions for the reductions between the intermediates of $\mathrm{BH}$ of cis-C18:2 and cis-C18:3.

\section{CONCLUSIONS}

Isomerization of cis-C18:2 to CLA was strongly inhibited by a low ruminal $\mathrm{pH}$ and by increasing concentrations of $c i s-\mathrm{C} 18: 3$ in the incubation media. On the contrary, increased concentrations of cis-C18:2 did not inhibit the $\mathrm{BH}$ of $\mathrm{cis}$-C18:2, but isomerization and second reduction steps showed a limited capacity. These results suggest that optimizing the CLA contents in the milk could be obtained with diets leading to a ruminal $\mathrm{pH}$ that is nearly neutral, and containing high amounts of cis-C18:2. Further research, based both on enzymological and in vivo studies, will be necessary to ascertain these modes of action and their effects on the concentration of CLA in the milk of cows.

\section{REFERENCES}

Beam, T. M., T. C. Jenkins, P. J. Moate, R. A. Kohn, and D. L. Palmquist. 2000. Effects of amount and source of fat on the rates of lipolysis and biohydrogenation of fatty acids in ruminal contents. J. Dairy Sci. 83:2564-2573.

Casper, D. P., D. J. Schingoethe, R. P. Middaugh, and R. J. Baer. 1988. Lactational responses of dairy cows to diets containing regular and high oleic sunflower seeds. J. Dairy Sci. 71:12671274.

Chin, S. F., W. Liu, J. M. Storkson, Y. L. Ha, and M. W. Pariza. 1992. Dietary sources of conjugated dienoic isomers of linoleic acid, a newly recognized class of anticarcinogens. J. Food Compos. Anal. 5:185-197.

Dhiman, T. R., G. R. Anand, L. D. Satter, and M. W. Pariza. 1999. Conjugated linoleic acid content of milk from cows fed different diets. J. Dairy Sci. 82:2146-2156.

Dhiman, T. R., L. D. Satter, M. W. Pariza, M. P. Galli, K. Albright, and M. X. Tolosa. 2000. Conjugated linoleic acid (CLA) content of milk from cows offered diets rich in linoleic and linolenic acid. J. Dairy Sci. 83:1016-1027.

Duckett, S. K., J. G. Andrae, and F. N. Owens. 2002. Effect of highoil corn or added corn oil on ruminal biohydrogenation of fatty acids and conjugated linoleic acid formation in beef steers fed finishing diets. J. Anim. Sci. 80:3353-3360.

Enjalbert, F., P. Eynard, M. C. Nicot, A. Troegeler-Meynadier, C. Bayourthe, and R. Moncoulon. 2003. In vitro versus in situ ruminal biohydrogenation of unsaturated fatty acids from a raw or extruded mixture of ground canola seed/canola meal. J. Dairy Sci. 86:351-359.

Griinari, J. M., D. A. Dwyer, M. A. Mac Guire, D. E. Bauman, D. L. Palmquist, and K. V. Nurmela. 1998. trans-Octadecenoic acids and milk fat depression in lactating dairy cows. J. Dairy Sci. 81:1251-1261.

Griinari, J. M., and D. E. Bauman. 1999. Biosynthesis of conjugated linoleic acid and its incorporation into meat and milk in rumi- nants. Pages 180-200 in Advances in Conjugated Linoleic Acid Research. Vol. 1. M. P. Yurawecz, M. M. Mossoba, J. K. G. Kramer, M. W. Pariza, and G. J. Nelson, ed. AOCS Press, Champaign, IL.

Griinari, J. M., B. A. Corl, S. H. Lacy, P. Y. Chouinard, K. V. Nurmela, and D. E. Bauman. 2000. Conjugated linoleic acid is synthesized endogenously in lactating dairy cows by delta(9)-desaturase. J. Nutr. 130:2285-2291.

Ha, Y. L., N. K. Grimm, and M. W. Pariza. 1989. Newly recognized anticarcinogenic fatty acids: Identification and quantification in natural and processed cheeses. J. Agric. Food Chem. 37:75-81.

Harfoot, C. G., R. C. Noble, and J. H. Moore. 1973. Factors influencing the extent of biohydrogenation of linoleic acid by rumen micro-organisms in vitro. J. Sci. Food Agric. 24:961-970.

Houseknecht, K. L., J. P. Van Den Heuvel, S. Y. Moya-Camarena, C. P. Portocarrero, L. W. Peck, K. P. Nickel, and M. A. Belury. 1998. Dietary conjugated linoleic acid normalizes impaired glucose tolerance in the Zucker diabetic fatty fa/fa rat. Biochem. Biophys. Res. Commun. 244:678-682.

Kepler, C. R., and S. B. Tove. 1967. Biohydrogenation of unsaturated fatty acids: Purification and properties of a linoleate $\Delta 12$ cis $-\Delta 11$ trans isomerase from Butyrivibrio fibrisolvens. J. Biol. Chem. 242:5686-5692.

Kepler, C. R., K. P. Hirons, J. J. McNeill, and S. B. Tove. 1966. Intermediates and products of the biohydrogenation of linoleic acid by Butyrivibrio fibrisolvens. J. Biol. Chem. 241:1350-1354.

Kim, Y. J., R. H. Liu, D. R. Bond, and J. B. Russell. 2000. Effect of linoleic acid concentration on conjugated linoleic acid production by Butyrivibrio fibrisolvens A38. Appl. Environ. Microbiol. 66:5226-5230.

Kim, Y. J., R. H. Liu, J. R. Rychlik, and J. B. Russell. 2002. The enrichment of a ruminal bacterium (Megasphaera elsdenii YJ4) that produces the trans-10, cis-12 isomer on conjugated linoleic acid. Appl. Environ. Microbiol. 66:5226-5230.

Kucuk, O., B. W. Hess, P. A. Ludden, and D. C. Rule. 2001. Effect of forage:concentrate ratio on ruminal digestion and duodenal flow of fatty acids in ewes. J. Anim. Sci. 79:2233-2240.

Loor, J. J., A. B. P. A. Bandara, and J. H. Herbein. 2002. Characterization of 18:1 and 18:2 isomers produced during microbial biohydrogenation of unsaturated fatty acids from canola and soya bean oil in the rumen of lactating cows. J. Anim. Physiol. Anim. Nutr. 86:422-432.

Martin, S. A., and T. C. Jenkins. 2002. Factors affecting conjugated linoleic acid and trans- $\mathrm{C}_{18: 1}$ fatty acid production by mixed ruminal bacteria. J. Anim. Sci. 80:3347-3352.

Meynadier, A., F. Enjalbert, M. C. Nicot, C. Bayourthe, and R. Moncoulon. 2002. Synthesis of conjugated linoleic acid (CLA) in dairy cow: Effects of feeding. In Proc. VII Symp. Toulouse-Munich, Toulouse, France.

Mosley, E. E., G. L. Powell, M. B. Riley, and T. C. Jenkins. 2002. Microbial biohydrogenation of oleic acid to trans isomers in vitro. J. Lipid Res. 43:290-296.

Nicolosi, R. J., K. V. Courtemanche, L. Laitinen, J. A. Scimeca, and P. J. Huth. 1993. Effect of feeding diets enriched in conjugated linoleic acid on lipoproteins and aortic atherogenesis in hamsters. Circulation 88(Suppl.):2458. (Abstr.)

Ørskov, E. R., and J. McDonald. 1979. The estimation of protein degradability in the rumen from incubation measurements weighed according to rate of passage. J. Agric. Sci. (Camb.) 92:499-503.

Park, Y., J. M. Storkson, K. J. Albright, W. Liu, and M. W. Pariza. 1999. Evidence that the trans-10,cis-12 isomer of conjugated linoleic acid induces body composition changes in mice. Lipids 34:235-241.

Parodi, P. W. 1999. Conjugated linoleic acid and other anticarcinogenic agents of bovine milk fat. J. Dairy Sci. 82:1339-1349.

Polan, C. E., J. J. McNeill, and S. B. Tove. 1964. Biohydrogenation of unsaturated fatty acids by rumen bacteria. J. Bacteriol. 88:1056-1064.

Reddy, P. V., J. L. Morrill, and T. G. Nagaraja. 1994. Release of free fatty acids from raw or processed soybeans and subsequent effects on fiber digestibilities. J. Dairy Sci. 77:3410-3416. 
Russell, J. B., and D. B. Dombrowski. 1980. Effect of $\mathrm{pH}$ on the efficiency of growth by pure cultures of rumen bacteria in continuous culture. Appl. Environ. Microbiol. 39:604-610.

Sukhija, P. S., and D. L. Palmquist. 1988. Rapid method for determination of total fatty acid content and composition of feedstuffs and feces. J. Agric. Food Chem. 36:1202-1206.

Van Nevel, C. J., and D. I. Demeyer. 1996. Influence of $\mathrm{pH}$ on lipolysis and biohydrogenation of soybean oil by rumen contents in vitro. Reprod. Nutr. Dev. 36:53-63.

Wang, J. H., M. K. Song, Y. S. Son, and M. B. Chang. 2002. Effect of concentrate level on the formation of conjugated linoleic acid and trans-octadecenoic acid by ruminal bacteria when incubated with oilseeds in vitro. Asian-Australas. J. Anim. Sci. 15:687-694.

Ward, P. F. V., T. W. Scott, and R. M. C. Dawson. 1964. The hydrogenation of unsaturated fatty acids in the ovine digestive tract. Biochem. J. 92:60-68.

Yamasaki, M., K. Kishihara, K. Mansho, Y. Ogino, M. Kasai, M. Sugano, H. Tachibana, and K. Yamada. 2000. Dietary conjugated linoleic acid increases immunoglobulin productivity of Sprague-Dawley rat spleen lymphocytes. Biosci. Biotechnol. Biochem. 64:2159-2164. 